\title{
Hyperfine structure investigations of atomic niobium with optogalvanic and laser-induced fluorescence spectroscopy in the near-infrared wavelength range
}

\author{
Gö. Başar ${ }^{1}$, Gü. Başar ${ }^{2}$, I. K. Öztürk ${ }^{1}$, A. Er ${ }^{1}$, F. Güzelçimen ${ }^{1}$, and S. Kröger ${ }^{3}$ \\ ${ }^{1}$ Istanbul University, Faculty of Science, Physics Department, 34134 Vezneciler, Istanbul, Turkey \\ e-mail: gbasar@istanbul.edu.tr \\ 2 Istanbul Technical University, Faculty of Science and Letters, Physics Engineering Department, 34469 Maslak, Istanbul, Turkey \\ ${ }^{3}$ Hochschule für Technik und Wirtschaft Berlin, Fachbereich 1, Wilhelminenhofstr. 75A, 12459 Berlin, Germany \\ e-mail: sophie.kroeger@htw-berlin.de
}

Received 19 May 2013 / Accepted 29 June 2013

\begin{abstract}
Aims. The aim of this work is to increase the amount of hyperfine structure data of atomic niobium (Nb I), which is needed for astrophysicists for the detailed analysis of new stellar spectra. Particular emphasis was placed on the investigation of energy levels with unknown hyperfine structure constants.

Methods. The hyperfine structure in the spectrum of $\mathrm{Nb}$ I was studied using laser-induced fluorescence spectroscopy and laser optogalvanic spectroscopy with a tuneable single-mode cw Ti:Sa laser in the wavelength range from $750 \mathrm{~nm}$ to $865 \mathrm{~nm}$. The Nb atoms were produced and excited in a liquid-nitrogen-cooled hollow-cathode plasma.

Results. We measured and analysed 81 spectral lines, 19 of which are not previously known from the literature. In total, the magnetic dipole hyperfine structure constants $A$ were determined for 28 energy levels of even and 53 energy levels of odd parity. The electric quadrupole hyperfine structure constants $B$ were only determined in a few cases, when the spectra were clearly resolved and/or when a level was found from several transitions. The magnetic dipole hyperfine structure constants $A$ of 13 even and 11 odd levels as well as the electric quadrupole hyperfine structure constants $B$ of 13 even and 17 odd levels are presented for the first time. For the other levels, improved values of hyperfine structure constants are given.

Conclusions. The hyperfine structure can have a significant effect on stellar absorption line profiles, and the corresponding abundances can be substantially overestimated if these effects are not taken into account. Therefore, a detailed consideration of the hyperfine structure is important for stellar abundance determinations. The present work substantially increases the knowledge of hyperfine structure of $\mathrm{Nb}$, which plays an important role in investigating the nucleosynthesis of heavy elements.
\end{abstract}

Key words. atomic data - line: profiles - techniques: spectroscopic - methods: laboratory

\section{Introduction}

We here continue our earlier systematic investigations of the spectrum of Nb I (Kröger \& Bouzed 2003; Kröger et al. 2004, 2007, 2010; Başar et al. 2008; Er et al. 2011). Our purpose is to supplement hyperfine structure (hfs) data for this element, in particular, to fill gaps for all energy levels of even parity with unknown hyperfine structure (hfs) constants.

Niobium $^{1}(\mathrm{Nb})$ is the third element of $4 \mathrm{~d}$ shell transition elements and belongs to the very few elements with only one stable isotope. The astrophysical interest of $\mathrm{Nb}$ hfs data was already extensively discussed in Kröger et al. (2010). A lot of work has already been done over the past 35 years to investigate the hfs of $\mathrm{Nb}$ using various spectroscopic methods. For the low-lying energy levels hfs constants have been determined with very high accuracy using atomic-beam magnetic-resonance method by Büttgenbach et al. (1975). Other high-resolution measurements have been made by Fraenkel et al. (1988) using laser and radio-frequency spectroscopy, and by some of us

\footnotetext{
Its name was columbium $(\mathrm{Cb})$ up to the 1950s.
}

(Başar et al. 2008), using Doppler-reduced saturation absorption spectroscopy. Doppler-limited measurements of hfs constants have been made using Fourier transform spectroscopy (Kröger et al. 2010; Er et al. 2011) and Doppler-limited laser spectroscopic methods (Singh \& Rao 1989; Singh et al. 1992; Bouzed et al. 2003; Kröger 2007). In addition to the experimental investigations, a theoretical analysis of hfs of atomic $\mathrm{Nb}$ has been performed by Büttgenbach \& Dicke (1975), Kröger \& Bouzed (2003), and Kröger et al. (2007).

Despite all this effort, for many energy levels the hfs constants are still unknown, some of them lying relatively low, i.e. lower than $25000 \mathrm{~cm}^{-1}$. Until now, the magnetic dipole hfs constants $A$ of 57 levels of even and 136 levels of odd parity as well as the electric quadrupole hfs constants $B$ of 32 levels of even and 30 levels of odd parity are known. In the present work, we increase the data by $24 A$ (13 for even and 11 for odd parity levels), filling all gaps for levels of even parity, which have had not yet known $A$ constants. Additionally, 31 new $B$ constants (13 for even and 18 for odd parity levels, respectively) were determined. 


\section{Experimental details}

The $\mathrm{Nb}$ atoms were produced and excited in a cooled hollowcathode plasma. The hollow-cathode lamp consists of mainly two anodes and a $20 \mathrm{~mm}$ long hollow cathode with a $3 \mathrm{~mm}$ inner diameter in which a 0.125 -mm-thick niobium foil was inserted. The hollow cathode was cooled by liquid nitrogen to reduce the Doppler width. A detailed explanation of the construction of the hollow-cathode lamp is given in Messnarz \& Guthöhrlein (2000). The discharge was operated at a Ne pressure of about 2 mbar and a current of 10 to $50 \mathrm{~mA}$. The current was chosen depending on the signal-to-noise ratio of the spectral line. The low current is favourable to reduce the Doppler width, whereas the high current increases the signal.

A continuous wave tuneable titan-sapphire (Ti:Sa) laser (Coherent MBR-110 pumped by Coherent Verdi $18 \mathrm{~W}$ ) was used in the wavelength range from $750 \mathrm{~nm}$ to $865 \mathrm{~nm}$ with a power of about $1.5 \mathrm{~W}$. Two small parts of the laser beam were split off by a beam sampler to measure spectral properties. The first beam part was directed to a home-made temperature stabilized confocal Fabry-Perot interferometer (FPI) with a free spectral range of about $300 \mathrm{MHz}$, which was used to measure the variation of the relative frequency during the scan of the laser wavelength. The spectrum from the FPI was used to calibrate the simultaneously measured atomic spectrum. The second part of the laser beam was coupled to a wavemeter (High Finesse WS6-200), which has an accuracy for the absolute frequency of $200 \mathrm{MHz}$ or $0.007 \mathrm{~cm}^{-1}$. By using a couple of dielectric mirrors, the main laser beam went through the hollow-cathode lamp after passing from the backside through the hole of the large diameter mirror that has a hole in the middle (outer diameter: $\varnothing=100 \mathrm{~mm}$, hole diameter: $\varnothing=3 \mathrm{~mm}$ ).

The experimental setup was constructed so that both the laser optogalvanic spectroscopy (LOGS) and laser-induced fluorescence spectroscopy (LIFS) could be applied simultaneously (see Fig. 1). The laser beam was amplitude-modulated by a mechanical chopper to apply a lock-in technique that recovered the signal deduced from LOGS and LIFS.

The optogalvanic signal was produced when the wavelength of the laser was resonant with the differences of energy levels of $\mathrm{Nb}$ or noble gas atoms. The change of voltage was measured across a ballast resistor. A detailed explanation of the optogalvanic effect can be found in Sasso (1990).

For LIFS measurements, the large-diameter hole mirror collected the divergent fluorescence light from the hollow cathode. The fluorescence light was collimated by a lens, directed to the monochromator by two large diameter mirrors $(\varnothing=100 \mathrm{~mm})$ and focused on the entrance slit by another lens. The monochromator (McPherson 607, $0.67 \mathrm{~m}$ focal length and a $(120 \mathrm{~mm} \times$ $140 \mathrm{~mm}$ ) large grating with 1200 lines/mm; photomultiplier PM R928 from Hamamatsu) was used as a fixed wavelength filter to measure only the fluorescence light arising from transition including one of the energy levels, which are involved in the transition excited by the laser. A detailed explanation of the LIFS method can be found in Shamim et al. (2011).

The two signals from LOGS and LIFS could be observed simultaneously. By scanning the laser wavelength, the hfs of the investigated spectral lines could be detected. For some lines, the signal-to noise ratio was better using LOGS than LIFS. For other lines, it was the opposite. For each line, the best method was chosen. For LIFS measurements, different fluorescence transitions were tried and the best was picked up.

In LOGS measurements, some lines were overlapping within their hfs pattern with other $\mathrm{Nb}$ or $\mathrm{Ne}$ lines. For these lines,

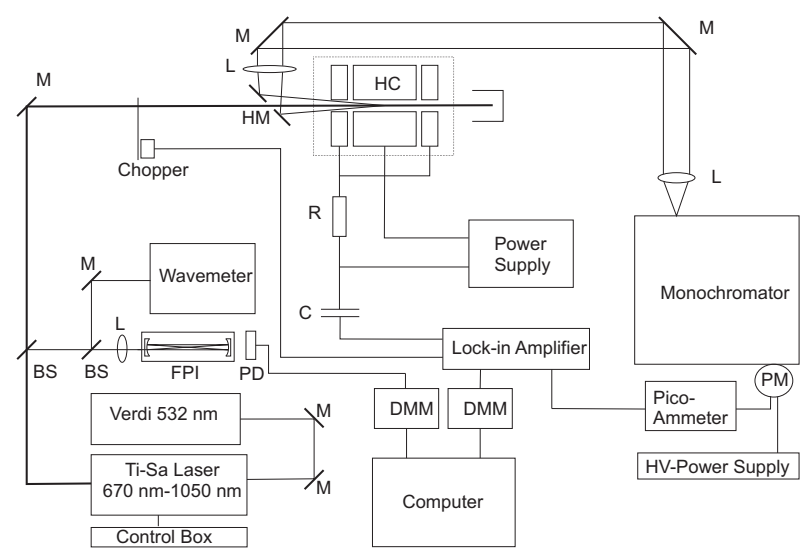

Fig. 1. Schematic overview of the experimental setup used for laser optogalvanic spectroscopy and laser-induced fluorescence spectroscopy; M: mirror, L: lens, BS: beam sampler, FPI: Fabry-Perot interferometer, R: resistor, C: capacitor, HC: hollow-cathode lamp, DMM: digital multimeter, PD: photodiode, HM: hole mirror, PM: photomultiplier, HV: high-voltage power supply.

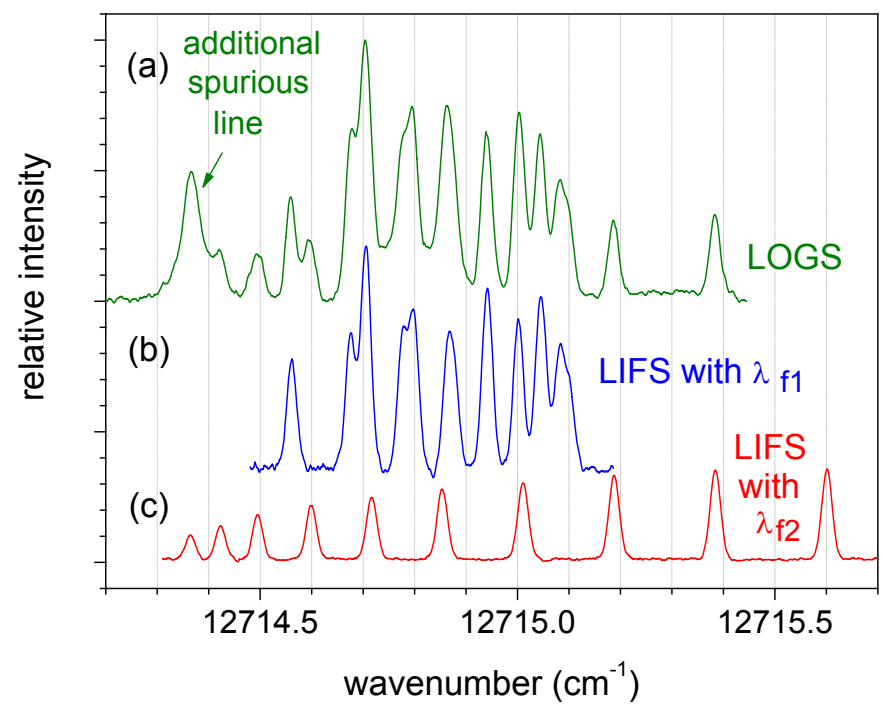

Fig. 2. Example for blended lines: a) Spectrum recorded by LOGS at around $12715 \mathrm{~cm}^{-1}$ showing the overlap of two $\mathrm{Nb}$ lines as well as another spurious line. b) Spectrum recorded by LIFS with fluorescence $\lambda_{\mathrm{f}}=532.15 \mathrm{~nm}$ : transition from $14899.26 \mathrm{~cm}^{-1}, J=$ $5 / 2 \longrightarrow 27614.10 \mathrm{~cm}^{-1}, J=5 / 2$ at $\lambda_{\text {air }}=786.266 \mathrm{~nm}$ or $\sigma_{\text {vac }}=12714.84 \mathrm{~cm}^{-1}$. c) Spectrum recorded by LIFS with fluorescence $\lambda_{\mathrm{f}}=581.94 \mathrm{~nm}$ : transition from $17476.22 \mathrm{~cm}^{-1}, J=$ $11 / 2 \longrightarrow 30191.25 \mathrm{~cm}^{-1}, J=13 / 2$ at $\lambda_{\text {air }}=786.255 \mathrm{~nm}$ or $\sigma_{\text {vac }}=$ $12715.03 \mathrm{~cm}^{-1}$.

LIFS was very convenient and offered the possibility to separate the lines by using different fluorescence channels. An example for overlapping hfs patterns is given in Fig. 2. The spectrum recorded with LOGS is compared with two spectra measured with LIFS using two different fluorescence wavelength. Only by using LIFS with two different fluorescence wavelengths was it possible to separate the lines.

\section{Selection of lines}

As mentioned above, the aim of the present work was to fill up gaps in the knowledge of hfs constants $A$, especially for 
levels of even parity. The classification program CLAss_LW from Windholz \& Guthöhrlein (2003) was used to search for transitions involving levels with unknown $A$ constants. A comprehensive list of experimental wavelengths and classifications for $\mathrm{Nb} \mathrm{I}$ and II, as well as a list of corresponding energy levels is given by Humphreys \& Meggers (1945) (nearly 70 years, old but still very useful). This list provides the basis for the classification program, supplemented by new energy levels from more recent references (Kröger et al. 2004, 2007), (resulting in the same list as the current state of the level list, given in the NIST atomic spectra database (NIST 2013)). The program additionally contains information about magnetic dipole and electric quadrupole hfs constants $A$ and $B$, if available. Using the Ritz combination principle and taking into account the selection rule for electric dipole transitions $(\Delta J=0, \pm 1 ; J=0 \leftrightarrow 0)$, the program calculates all possible transitions to and from a chosen energy level. The program does not consider transition probabilities and of course provides much more lines than listed in the wavelength table of Humphreys \& Meggers (1945). Therefore, not all transitions calculated by the Ritz combination principle could be found with our experimental conditions.

We measured and classified 81 spectral transitions (see Table 1). Sixty-two of these lines have already been listed in the wavelength tables from Humphreys \& Meggers (1945), 14 without classification. The classification for these lines was deduced from the classification program CLAss_LW using the hfs patterns as fingerprint. Nineteen lines were not previously known from the literature.

\section{Hyperfine structure analysis}

The hyperfine structure (hfs) describes higher-order interactions of the nuclear moments with the magnetic and electric fields produced by the electrons at the site of the nucleus. It results in a splitting of a fine structure energy level $E$, (characterized by the total electronic angular momentum quantum number $J$ ), into hfs sublevels when an isotope has a nuclear spin $I$ greater than zero. The hfs sublevels are characterized by the total angular momentum quantum number $F$, which can take values from $|J-I|$ to $(J+I)$. Hence, the number of hfs sublevels is equal to the minimum of $(2 J+1)$ or $(2 I+1)$. The hfs interaction energy $E_{\mathrm{hfs}}$ of a hfs sublevel is given by

$E_{\mathrm{hfs}}(F)=A \frac{K}{2}+B \frac{3 K(K+1)-4(I(I+1) J(J+1)}{8 I(2 I-1) J(2 J-1)}$,

where $A$ and $B$ are the hfs constants for the magnetic dipole and electric quadrupole interaction, respectively, and

$K=F(F+1)-I(I+1)-J(J+1)$.

The first term in Eq. (1) is caused by the magnetic dipole interaction and the second term by the electric quadrupole interaction. $A$ and $B$ are specific for each fine structure level. If only the magnetic dipole hfs is taken into account, the energy difference between hfs sublevels can be simply calculated by the Landé interval rule:

$E_{\mathrm{hfs}}(F+1)-E_{\mathrm{hfs}}(F)=A(F+1)$.

The selection rule for optical transitions between hfs sublevels is given by

$\Delta F=0, \pm 1 \quad(F=0 \leftrightarrow 0)$.
The relative intensity of hfs transitions is given by

rel.int. $=\left(2 F_{u}+1\right)\left(2 F_{l}+1\right)\left\{\begin{array}{ccc}I & F_{u} & J_{u} \\ 1 & J_{l} & F_{l}\end{array}\right\}$

where the indices $u$ and $l$ indicate the upper and lower level, respectively. Transitions with $\Delta J=\Delta F$ have the highest intensity.

The only stable niobium isotope ${ }^{93} \mathrm{Nb}$ has a nuclear spin of $I=9 / 2$ and a large magnetic dipole moment of $\mu_{I}=$ $+6.1705(3) \mu_{N}$ (Lederer \& Shirley 1978). Therefore it is reasonable to apply Doppler-limited experimental techniques to determine the magnetic dipole hfs constants $A$. The comparatively small electric quadrupole moment of $Q=-0.36$ (7) barn (Lederer \& Shirley 1978) leads to a weak deviation of the hyperfine splitting from the interval rule (see Eq. (2)), which is not always detectable in Doppler-limited spectra.

For analysing the recorded spectra, the wave number axis were linearised using the free spectral range of the FPI. The free spectral range is calibrated to 299.0010 (8) $\mathrm{MHz}$, which corresponds to a relative accuracy of $3 \times 10^{-4} \%$.

To obtain the hfs constants $A$ and $B$, the linearised spectra were fitted using the program FITTER (Guthöhrlein 2004), which takes into consideration Eq. (1). The fit parameters were

- the centre of gravity of the total hfs;

- the $A$ and $B$ constants of the upper and the lower level;

- the intensities and the Gaussian and Lorentzian parts of the Voigt profile of the individual hfs components;

- two parameters to take into account height and slope of the background.

For all measured lines the observed intensity ratios of the hfs components differ from the theoretical intensity ratios given in Eq. (3). This is caused by hyperfine pumping and by the saturation effect due to the high power of the laser. This effect results in an intensity reduction and broadening of the strong hfs components and leads to an apparent intensity increase of the weak components. As a consequence, the ratio of the intensities of the components is not in accordance with the theoretical ratios. The Lorentzian contribution differs for the individual hfs components, whereas the Gaussian contribution is the same for all hfs components of a line. For this reason, the parameter for the Gaussian half width was set to the same value for all hfs components of a line, whereas the parameters for Lorentz half width and intensity may vary. To illustrate the magnitude of intensity increase of the weak components, a spectrum of a fully resolved line is shown in Fig. 3 together with the theoretical relative intensities, given as arrows. The arrows are normalised to the strongest hfs component. Intensity increases up to factors higher than 6 are measured.

Depending on the discharge current and on the wavelength, the Gaussian line width varied from $540 \mathrm{MHz}$ to $820 \mathrm{MHz}$ for the different lines.

As discussed above, the influence of the electric quadrupole interaction on the hfs is small. Therefore, it was possible to determine reliable values for the $B$ constants only when a line had at least four clearly resolved individual hfs components. In these cases, the $B$ constants were fitted as free parameters. In all other cases, the $B$ constants were fixed to be equal to zero (except for a few unresolved lines, where $A$ and $B$ constants for one level were fixed equal to previously known values, see below).

All spectra with clearly resolved hfs components (as for example the line shown in Fig. 3) are fitted with individual Lorentz half widths and individual intensity parameters for each hfs component. In some cases, for the weakest hfs components of these 
Table 1. Nb I lines investigated by means of laser optogalvanic spectroscopy (LOGS) or laser-induced fluorescence spectroscopy (LIFS).

\begin{tabular}{|c|c|c|c|c|c|c|c|c|}
\hline$\lambda_{\text {air }}(\mathrm{nm})$ & $\sigma_{\text {vac }}\left(\mathrm{cm}^{-1}\right)$ & Int. & Comment & $E_{1}\left(\mathrm{~cm}^{-1}\right)$ & $J_{1}$ & $E_{\mathrm{u}}\left(\mathrm{cm}^{-1}\right)$ & $J_{\mathrm{u}}$ & Method, $\lambda_{f}(\mathrm{~nm})$ \\
\hline 861.445 & 11605.22 & 20 & & 16828.52 & $9 / 2$ & 28433.74 & $9 / 2$ & LIFS, 527.94 \\
\hline 854.725 & 11696.46 & 20 & & 8410.90 & $1 / 2$ & 20107.36 & $1 / 2$ & LOGS \\
\hline 852.696 & 11724.29 & 50 & & 10922.74 & $7 / 2$ & 22647.03 & $5 / 2$ & LOGS \\
\hline 847.596 & 11794.84 & 15 & & 9043.14 & $5 / 2$ & 20837.98 & $5 / 2$ & LOGS \\
\hline 845.672 & 11821.67 & - & $\mathrm{nl}$ & 19556.91 & $9 / 2$ & 31378.58 & $11 / 2$ & LIFS, 491.64 \\
\hline 843.981 & 11845.35 & 25 & & 12357.70 & $9 / 2$ & 24203.05 & $11 / 2$ & LIFS, 467.21 \\
\hline 842.317 & 11868.76 & - & $\mathrm{nl}$ & 19931.98 & $5 / 2$ & 31800.74 & $7 / 2$ & LOGS \\
\hline 840.627 & 11892.62 & 15 & $\mathrm{~B}(\mathrm{Ne})$ & 15467.08 & $5 / 2$ & 27359.70 & $5 / 2$ & LIFS, 535.90 \\
\hline 839.231 & 11912.40 & - & $\mathrm{nl}$ & 20060.84 & $7 / 2$ & 31973.24 & $7 / 2$ & LIFS, 605.67 \\
\hline 835.003 & 11972.72 & 20 & & 8410.90 & $1 / 2$ & 20383.62 & $3 / 2$ & LOGS \\
\hline 834.601 & 11978.48 & 60 & & 11044.08 & $9 / 2$ & 23022.56 & $7 / 2$ & LIFS, 539.43 \\
\hline 833.743 & 11990.81 & - & $\mathrm{nl}$ & 19034.71 & $7 / 2$ & 31025.52 & $7 / 2$ & LOGS \\
\hline 833.284 & 11997.42 & - & $\mathrm{nl}$ & 14899.26 & $5 / 2$ & 26896.68 & $7 / 2$ & LIFS, 559.95 \\
\hline 829.365 & 12054.10 & 3 & $\mathrm{~B}(\mathrm{Ne})$ & 13145.71 & $9 / 2$ & 25199.81 & $9 / 2$ & LIFS, 407.97 \\
\hline 827.769 & 12077.35 & - & $\mathrm{nl}, \mathrm{B}(\mathrm{Nb})$ & 15282.35 & $7 / 2$ & 27359.70 & $5 / 2$ & LIFS, 535.90 \\
\hline 827.490 & 12081.42 & - & $\mathrm{nl}$ & 19931.98 & $5 / 2$ & 32013.40 & $5 / 2$ & LOGS \\
\hline 826.231 & 12099.82 & 4 & & 10922.74 & $7 / 2$ & 23022.56 & $7 / 2$ & LOGS \\
\hline 823.682 & 12137.27 & 3 & & 15282.35 & $7 / 2$ & 27419.62 & $9 / 2$ & LOGS \\
\hline 822.609 & 12153.10 & 3 & nc B(?) & 20060.84 & $7 / 2$ & 32213.94 & $9 / 2$ & LIFS, 436.84 \\
\hline 821.125 & 12175.06 & 3 & $\mathrm{nc}$ & 14211.30 & $3 / 2$ & 26386.36 & $5 / 2$ & LIFS, 474.06 \\
\hline 819.065 & 12205.69 & 4 & & 15460.77 & $1 / 2$ & 27666.46 & $1 / 2$ & LOGS \\
\hline 818.103 & 12220.04 & - & $\mathrm{nl}$ & 22936.90 & $7 / 2$ & 35156.94 & $9 / 2$ & LIFS, 434.28 \\
\hline 817.623 & 12227.21 & 5 & & 15439.25 & $3 / 2$ & 27666.46 & $1 / 2$ & LOGS \\
\hline 816.847 & 12238.83 & 3 & $\mathrm{nc}$ & 19568.72 & $5 / 2$ & 31807.55 & $5 / 2$ & LOGS \\
\hline 813.519 & 12288.89 & 80 & & 11247.88 & $11 / 2$ & 23536.77 & $9 / 2$ & LIFS, 444.58 \\
\hline 811.682 & 12316.71 & - & $\mathrm{nl}$ & 19931.98 & $5 / 2$ & 32248.69 & $3 / 2$ & LIFS, 424.63 \\
\hline 810.783 & 12330.36 & 2 & & 15467.08 & $5 / 2$ & 27797.44 & $5 / 2$ & LIFS, 526.99 \\
\hline 810.528 & 12334.28 & - & $\mathrm{nl}$ & 23010.58 & $9 / 2$ & 35344.86 & $11 / 2$ & LIFS, 434.90 \\
\hline 808.515 & 12364.96 & 4 & $\mathrm{nc}$ & 19568.72 & $5 / 2$ & 31933.68 & $5 / 2$ & LOGS \\
\hline 803.773 & 12437.91 & 4 & & 13629.15 & $1 / 2$ & 26067.06 & $3 / 2$ & LOGS \\
\hline 803.606 & 12440.49 & 5 & nc & 20060.84 & $7 / 2$ & 32501.33 & $7 / 2$ & LIFS, 490.08 \\
\hline 802.878 & 12451.77 & 10 & & 15467.08 & $5 / 2$ & 27918.85 & $3 / 2$ & LOGS \\
\hline 802.471 & 12458.08 & 4 & & 15460.77 & $1 / 2$ & 27918.85 & $3 / 2$ & LOGS \\
\hline 801.766 & 12469.04 & 5 & & 9043.14 & $5 / 2$ & 21512.18 & $7 / 2$ & LIFS, 473.34 \\
\hline 801.087 & 12479.60 & 3 & & 15439.25 & $3 / 2$ & 27918.85 & $3 / 2$ & LOGS \\
\hline 800.755 & 12484.78 & 3 & & 12288.25 & $3 / 2$ & 24773.03 & $5 / 2$ & LOGS \\
\hline 800.248 & 12492.69 & 8 & & 11044.08 & $9 / 2$ & 23536.77 & $9 / 2$ & LOGS \\
\hline 798.005 & 12527.81 & 4 & & 14899.26 & $5 / 2$ & 27427.07 & $7 / 2$ & LOGS \\
\hline 794.565 & 12582.04 & - & $\mathrm{nl}$ & 23048.58 & $11 / 2$ & 35630.62 & $11 / 2$ & LIFS, 414.72 \\
\hline 792.281 & 12618.32 & 3 & & 15460.77 & $1 / 2$ & 28079.09 & $3 / 2$ & LOGS \\
\hline 790.932 & 12639.84 & 3 & & 15439.25 & $3 / 2$ & 28079.09 & $3 / 2$ & LOGS \\
\hline 790.209 & 12651.40 & 4 & & 10922.74 & $7 / 2$ & 23574.14 & $5 / 2$ & LOGS \\
\hline 789.857 & 12657.03 & 10 & $\mathrm{nc}$ & 19556.91 & $9 / 2$ & 32213.94 & $9 / 2$ & LOGS \\
\hline 788.526 & 12678.40 & 60 & & 11524.65 & $13 / 2$ & 24203.05 & $11 / 2$ & LOGS \\
\hline 788.429 & 12679.97 & - & $\mathrm{nl}$ & 19568.72 & $5 / 2$ & 32248.69 & $3 / 2$ & LIFS, 424.63 \\
\hline 787.741 & 12691.04 & - & $\mathrm{nl}$ & 19931.98 & $5 / 2$ & 32623.02 & $3 / 2$ & LIFS, 485.19 \\
\hline 787.341 & 12697.48 & 50 & & 14899.26 & $5 / 2$ & 27596.74 & $7 / 2$ & LOGS \\
\hline 786.266 & 12714.84 & 10 & $\mathrm{~B}(\mathrm{Nb})$ & 14899.26 & $5 / 2$ & 27614.10 & $5 / 2$ & LIFS, 532.15 \\
\hline 786.255 & 12715.03 & - & $\mathrm{nl}, \mathrm{B}(\mathrm{Nb})$ & 17476.22 & $11 / 2$ & 30191.25 & $13 / 2$ & LIFS, 581.94 \\
\hline 785.793 & 12722.50 & - & $\mathrm{nl}$ & 19931.98 & $5 / 2$ & 32654.48 & $5 / 2$ & LIFS, 430.63 \\
\hline 785.604 & 12725.56 & 15 & $\mathrm{~B}(\mathrm{Ne})$ & 14211.30 & $3 / 2$ & 26936.86 & $3 / 2$ & LIFS, 539.63 \\
\hline 782.696 & 12772.84 & - & $\mathrm{nl}$ & 19034.71 & $7 / 2$ & 31807.55 & $5 / 2$ & LIFS, 610.76 \\
\hline 778.709 & 12838.24 & 10 & $\mathrm{nc}$ & 20060.84 & $7 / 2$ & 32899.08 & $7 / 2$ & LIFS, 410.96 \\
\hline 777.208 & 12863.03 & 5 & $\mathrm{nc}$ & 20060.84 & $7 / 2$ & 32923.87 & $9 / 2$ & LIFS, 480.94 \\
\hline 775.090 & 12898.18 & 10 & & 14899.26 & $5 / 2$ & 27797.44 & $5 / 2$ & LOGS \\
\hline
\end{tabular}

Notes. $E_{1}, J_{1}, E_{\mathrm{u}}$ and $J_{\mathrm{u}}$ are the energy and total electronic angular momentum quantum number of the lower and upper level, respectively; intensities Int. according to Humphreys \& Meggers (1945), energy levels according to Humphreys \& Meggers (1945) and Kröger et al. (2004, 2007); in the last column the fluorescence wavelength $\lambda_{\mathrm{f}}$ in air is given for the LIFS measurements; nl: new line; nc: new classification; $\mathrm{B}(\mathrm{Ne})$ : a neon line, $\mathrm{B}(\mathrm{Nb})$ blend by a niobium line, $\mathrm{B}($ ?): blend by unclassified line. 
Table 1. continued.

\begin{tabular}{ccccccccc}
\hline \hline$\lambda_{\text {air }}(\mathrm{nm})$ & $\sigma_{\text {vac }}\left(\mathrm{cm}^{-1}\right)$ & Int. & Comment & $E_{1}\left(\mathrm{~cm}^{-1}\right)$ & $J_{1}$ & $E_{\mathrm{u}}\left(\mathrm{cm}^{-1}\right)$ & $J_{\mathrm{u}}$ & Method, $\lambda_{f}(\mathrm{~nm})$ \\
\hline 773.586 & 12923.25 & 6 & & 13629.15 & $1 / 2$ & 26552.40 & $1 / 2$ & LIFS, 578.70 \\
773.026 & 12932.61 & 3 & $\mathrm{nc} \mathrm{B}(\mathrm{Ne})$ & 19568.72 & $5 / 2$ & 32501.33 & $7 / 2$ & LIFS, 490.08 \\
772.673 & 12938.53 & - & $\mathrm{nl}, \mathrm{B}(\mathrm{Nb})$ & 19034.71 & $7 / 2$ & 31973.24 & $7 / 2$ & LIFS, 605.67 \\
772.403 & 12943.05 & 3 & $\mathrm{nc}$ & 20060.84 & $7 / 2$ & 33003.89 & $7 / 2$ & LOGS \\
771.680 & 12955.17 & 4 & & 11247.88 & $11 / 2$ & 24203.05 & $11 / 2$ & LIFS, 467.21 \\
770.737 & 12971.03 & 5 & & 11044.08 & $9 / 2$ & 24015.11 & $7 / 2$ & LOGS \\
770.308 & 12978.25 & - & $\mathrm{nl}$ & 15467.08 & $5 / 2$ & 28445.33 & $5 / 2$ & LIFS, 444.71 \\
768.660 & 13006.08 & 3 & & 15439.25 & $3 / 2$ & 28445.33 & $5 / 2$ & LIFS, 527.62 \\
767.833 & 13020.08 & 4 & & 13145.71 & $9 / 2$ & 26165.79 & $7 / 2$ & LIFS, 583.86 \\
766.276 & 13046.54 & 10 & $\mathrm{nc}$ & 18332.04 & $11 / 2$ & 31378.58 & $11 / 2$ & LOGS \\
766.162 & 13048.48 & 10 & $\mathrm{nc}$ & 19556.91 & $9 / 2$ & 32605.39 & $9 / 2$ & LOGS \\
765.904 & 13052.87 & 12 & $\mathrm{nc}$ & 19034.71 & $7 / 2$ & 32087.58 & $7 / 2$ & LOGS \\
764.179 & 13082.34 & 1 & & 15467.08 & $5 / 2$ & 28549.42 & $5 / 2$ & LIFS, 429.96 \\
763.979 & 13085.76 & 12 & $\mathrm{nc}$ & 19568.72 & $5 / 2$ & 32654.48 & $5 / 2$ & LOGS \\
763.815 & 13088.58 & 15 & & 13629.15 & $1 / 2$ & 26717.73 & $1 / 2$ & LOGS \\
762.557 & 13110.17 & 4 & & 15439.25 & $3 / 2$ & 28549.42 & $5 / 2$ & LOGS \\
762.113 & 13117.81 & 8 & & 10126.06 & $1 / 2$ & 23243.87 & $3 / 2$ & LIFS, 452.34 \\
758.561 & 13179.23 & - & $\mathrm{nl}$ & 19034.71 & $7 / 2$ & 32213.94 & $9 / 2$ & LIFS, 436.84 \\
758.526 & 13179.83 & 20 & $\mathrm{~B}(?)$ & 14899.26 & $5 / 2$ & 28079.09 & $3 / 2$ & LIFS, 438.84 \\
758.320 & 13183.41 & 20 & & 12982.38 & $7 / 2$ & 26165.79 & $7 / 2$ & LIFS, 583.86 \\
754.338 & 13253.01 & 4 & & 15282.35 & $7 / 2$ & 28535.36 & $7 / 2$ & LIFS, 442.94 \\
754.017 & 13258.65 & 4 & & 11247.88 & $11 / 2$ & 24506.53 & $9 / 2$ & LIFS, 460.68 \\
753.538 & 13267.07 & 10 & & 15282.35 & $7 / 2$ & 28549.42 & $5 / 2$ & LIFS, 429.96 \\
751.977 & 13294.62 & 50 & & 13145.71 & $9 / 2$ & 26440.33 & $9 / 2$ & LIFS, 590.05 \\
751.759 & 13298.47 & 4 & $\mathrm{nc}$ & 19034.71 & $7 / 2$ & 32333.18 & $7 / 2$ & LOGS \\
751.237 & 13307.71 & 15 & & 13629.15 & $1 / 2$ & 26936.86 & $3 / 2$ & LOGS \\
\hline
\end{tabular}

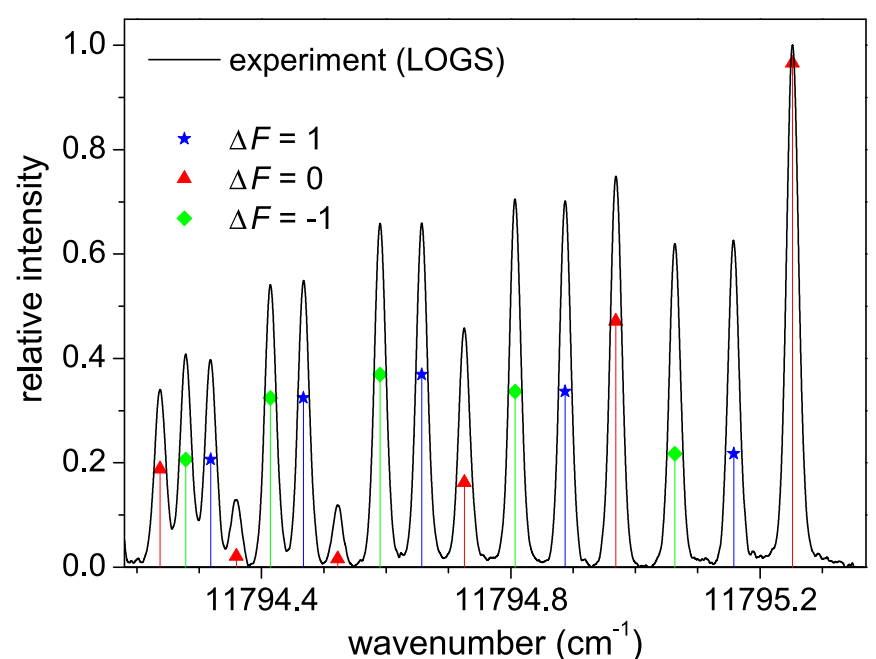

Fig. 3. Fully resolved line to illustrate the magnitude of intensity increase of the weak components. Theoretical relative intensities calculated following Eq. (3) are given as arrows; the arrows are normalised to the strongest hfs component: transition from $9043.14 \mathrm{~cm}^{-1}$, $J=5 / 2 \longrightarrow 20837.98 \mathrm{~cm}^{-1}, J=5 / 2$ at $\lambda_{\text {air }}=847.596 \mathrm{~nm}$ or $\sigma_{\text {vac }}=11794.84 \mathrm{~cm}^{-1}$.

lines, the fit leads to unreliable values of the Lorentz half width. Then, these parameters were coupled to the same parameter of an other hfs component with the same $\Delta F$.

To analyse the spectra that showed only partly resolved hfs, the number of parameters had to be reduced. This was made in different gradings, as described in the following. Due to the dependence of the saturation effect from the intensity of the hfs components, it made sense to couple profile parameters of hfs components with the same $\Delta F$ value, because their intensities are similar in size.

As a first measure, for lines with a partly resolved hfs (as for example shown in Fig. 4a) the parameter for the Lorentzian width were coupled to the same value for each group of hfs components with same $\Delta F$.

If this was not sufficient, depending on the degree of resolution, in some cases the parameter for the Lorentzian width were coupled to the same value for all hfs components and the intensity parameters were additionally coupled for one or more groups of hfs components with the same $\Delta F$ according to the theoretical ratios. An example for such a line is given in Fig. 4b.

Some lines look as if they are completely resolved, although this is not the case and most peaks include two or three hfs components. This occurred when one of the involved levels had a very low $A$ constant (i.e. lower than $50 \mathrm{MHz}$ with FWHM of about $600 \mathrm{MHz}$ ). For example, the lowest curve in Fig. 2 exhibits this behaviour. To highlight the hfs components, this line is shown again in Fig. $4 \mathrm{c}$ together with the fit results.

To analyse spectra with almost unresolved hfs, the number of parameters had to be reduced even more. For this purpose, in addition to all couplings discussed above, the hfs constants $A$ and $B$ of one level were fixed when they were previously known from the literature. An example for such a line is given in Fig. $4 \mathrm{~d}$. A list of the hfs constants from the literature and from this work that were fixed during a fit is given in Table 2. 
A\&A 556, A103 (2013)
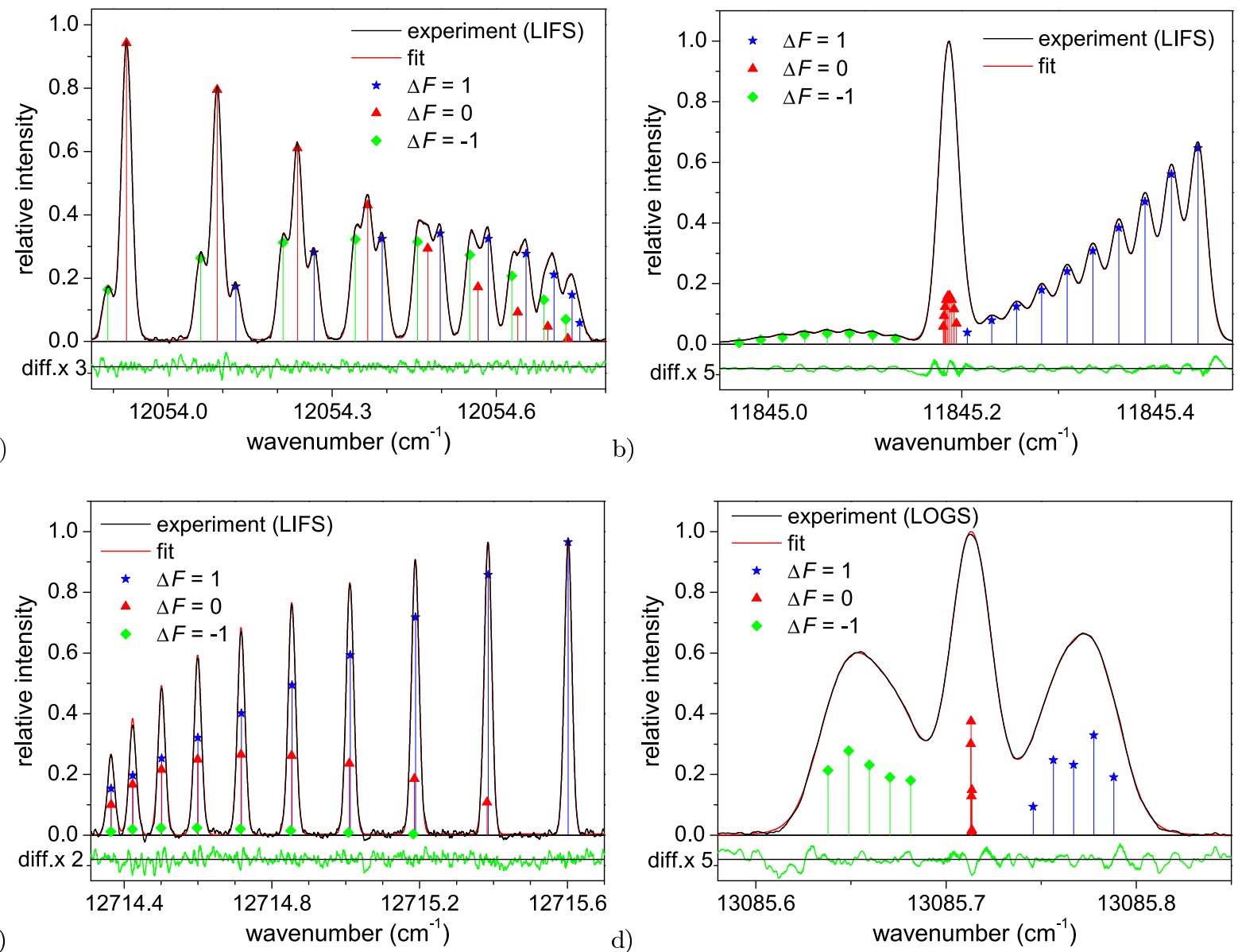

Fig. 4. Hyperfine spectra of the $\mathrm{Nb}$ I lines measured with LIFS or LOGS together with the best fitted curve. The hyperfine components are marked by the difference $\Delta F$ of the total angular momenta of the lower and upper hyperfine levels. In the lower part of the each figure the residuals between experimental and best fitted curves are given, multiplied by the factor indicated at left side of the graphs. a) Example for a line with a rather well resolved hfs, fitted with coupled parameters for the Lorentzian width for each group of hfs components with same $\Delta F$ : transition from $13145.71 \mathrm{~cm}^{-1}, J=9 / 2 \longrightarrow 25199.81 \mathrm{~cm}^{-1}, J=9 / 2$ at $\lambda_{\text {air }}=829.365 \mathrm{~nm}$ or $\sigma_{\text {vac }}=12054.10 \mathrm{~cm}^{-1}$. b) Example for a partly resolved line, fitted with same parameter for the Lorentzian width for all hfs components and coupled intensity parameters for all hfs components with $\Delta F=0$ : transition from $12357.70 \mathrm{~cm}^{-1}, J=9 / 2 \longrightarrow 24203.05 \mathrm{~cm}^{-1}, J=11 / 2$ at $\lambda_{\text {air }}=843.981 \mathrm{~nm}$ or $\sigma_{\text {vac }}=11845.35 \mathrm{~cm}^{-1}$. c) Example for a line that looks like completely resolved, but most peaks include two or three hfs components: transition from $17476.22 \mathrm{~cm}^{-1}, J=11 / 2 \longrightarrow 30191.25 \mathrm{~cm}^{-1}$, $J=13 / 2$ at $\lambda_{\text {air }}=786.255 \mathrm{~nm}$ or $\sigma_{\text {vac }}=12715.03 \mathrm{~cm}^{-1}$. d) Example for an unresolved line fitted with coupled profile parameters, $B$ constants fixed to zero and fixed $A$ constant of the lower level: transition from $19568.72 \mathrm{~cm}^{-1}, J=5 / 2 \longrightarrow 32654.48 \mathrm{~cm}^{-1}, J=5 / 2$ at $\lambda_{\text {air }}=763.979 \mathrm{~nm}$ or $\sigma_{\mathrm{vac}}=13085.76 \mathrm{~cm}^{-1}$.

Table 2. Hyperfine structure constants $A$ and $B$ from the literature and from this work, which were fixed during a fit.

\begin{tabular}{lcccccc}
\hline \hline$E\left(\mathrm{~cm}^{-1}\right)$ & Config., Term & $J$ & Method & $A(\mathrm{MHz})$ & $B(\mathrm{MHz})$ & Ref. \\
\hline even parity & & & & & & \\
10126.06 & $4 \mathrm{~d}^{3}\left({ }^{2} \mathrm{P}\right) 5 \mathrm{~s}^{2}{ }^{2} \mathrm{P}$ & $1 / 2$ & LRF & $323.6590(4)$ & 0 & $(1)$ \\
11247.88 & $4 \mathrm{~d}^{4}\left({ }^{3} \mathrm{H}\right) 5 \mathrm{~s}{ }^{4} \mathrm{H}$ & $11 / 2$ & FTS & $592(3)$ & - & $(2)$ \\
14211.30 & $4 \mathrm{~d}^{4}\left({ }^{3} \mathrm{P}\right) 5 \mathrm{~s}{ }^{4} \mathrm{P}$ & $3 / 2$ & LIFS & $1414.5(2)$ & $31(4)$ & $(3)$ \\
14899.26 & $4 \mathrm{~d}^{4}\left({ }^{3} \mathrm{P}\right) 5 \mathrm{~s}{ }^{4} \mathrm{P}$ & $5 / 2$ & LIFS & $1017.6(1.4)$ & $7(4)$ & t.w. \\
19034.71 & $4 \mathrm{~d}^{4}\left({ }^{3} \mathrm{G}\right) 5 \mathrm{~s}{ }^{2} \mathrm{G}$ & $7 / 2$ & LIFS & $477.6(8)$ & $57(40)$ & t.w. \\
19568.72 & $4 \mathrm{~d}^{4}\left({ }^{1} \mathrm{~F}\right) 5 \mathrm{~s}{ }^{2} \mathrm{~F}$ & $5 / 2$ & LIFS & $322.4(4)$ & - & t.w. \\
odd parity & & & & & & \\
24015.11 & $4 \mathrm{~d}^{3}\left({ }^{4} \mathrm{~F}\right) 5 \mathrm{~s}\left({ }^{5} \mathrm{~F}\right) 5 \mathrm{p}{ }^{4} \mathrm{~F}$ & $7 / 2$ & SAS & $591.8(3)$ & $108(17)$ & $(4)$ \\
24506.53 & $4 \mathrm{~d}^{3}\left({ }^{4} \mathrm{~F}\right) 5 \mathrm{~s}\left({ }^{5} \mathrm{~F}\right) 5 \mathrm{p}{ }^{4} \mathrm{~F}$ & $9 / 2$ & SAS & $593.0(4)$ & $148(37)$ & $(4)$ \\
26936.86 & $4 \mathrm{~d}^{4}\left({ }^{5} \mathrm{D}\right) 5 \mathrm{p}{ }^{6} \mathrm{D}$ & $3 / 2$ & FTS & $39.9(6)$ & - & $(5)$ \\
30191.25 & $4 \mathrm{~d}^{3}\left({ }^{2} \mathrm{H}\right) 5 \mathrm{~s}\left({ }^{3} \mathrm{H}\right) 5 \mathrm{p}{ }^{4} \mathrm{H}$ & $13 / 2$ & FTS & $598.8(5.3)$ & - & $(2)$ \\
31378.58 & $4 \mathrm{~d}^{3}\left({ }^{2} \mathrm{G}\right) 5 \mathrm{~s}\left({ }^{1} \mathrm{G}\right) 5 \mathrm{p}{ }^{2} \mathrm{H}$ & $11 / 2$ & LIFS & $791.1(1.2)$ & $-236(50)$ & t.w. \\
35344.86 & $4 \mathrm{~d}^{4}\left({ }^{3} \mathrm{H}\right) 5 \mathrm{p}{ }^{4} \mathrm{I}$ & $11 / 2$ & FTS & $510.0(3.1)$ & - & $(5)$ \\
\hline
\end{tabular}

Notes. LRF - laser radio-frequency double resonance, FTS - Fourier transform spectroscopy, LIFS - laser-induced fluorescence spectroscopy, SAS - saturation absorption spectroscopy.

References. t.w.: this work; (1) Fraenkel et al. (1988); (2) Er et al. (2011); (3) Bouzed et al. (2003); (4) Başar et al. (2008); (5) Kröger et al. (2010). 
Gö. Başar et al.: Hfs investigations of Nb I with LOGS and LIFS in the near-IR

Table 3. Experimental hyperfine structure constants $A_{\exp }$ and $B_{\exp }$ (in $\mathrm{MHz}$ ) of the levels of even parity of $\mathrm{Nb}$ I together with comparative values $A_{\text {ref }}$ and $B_{\text {ref }}$, if available.

\begin{tabular}{|c|c|c|c|c|c|c|c|c|c|c|}
\hline$E\left(\mathrm{~cm}^{-1}\right)$ & Config., Term & $J$ & $\lambda_{\text {air }}(\mathrm{nm})$ & $A_{\text {exp }}(\mathrm{MHz})$ & $A_{\text {mean }}(\mathrm{MHz})$ & $B_{\exp }(\mathrm{MHz})$ & $B_{\text {mean }}(\mathrm{MHz})$ & $A_{\text {ref }}(\mathrm{MHz})$ & $B_{\text {ref }}(\mathrm{MHz})$ & Ref. \\
\hline 8410.90 & $4 d^{4}\left({ }^{5} D\right) 5 s{ }^{4} D$ & $1 / 2$ & $\begin{array}{l}854.725 \\
835.003\end{array}$ & $\begin{array}{l}1996.7(2) \\
1995.8(1.6)\end{array}$ & $1996.7(1)$ & $\begin{array}{l}0 \\
0\end{array}$ & 0 & 1996(1) & 0 & (1) \\
\hline 9043.14 & $4 d^{4}\left({ }^{5} D\right) 5 s{ }^{4} D$ & $5 / 2$ & $\begin{array}{l}847.596 \\
801.766\end{array}$ & $\begin{array}{l}-407.6(2) \\
-407.5(6)\end{array}$ & $-407.59(3)$ & $\begin{array}{l}41(8) \\
35(8)\end{array}$ & $38(3)$ & $-407.8606(43)$ & $35.060(75)$ & (2) \\
\hline 10922.74 & $4 d^{4}\left({ }^{3} \mathrm{H}\right) 5 \mathrm{~s}{ }^{4} \mathrm{H}$ & $7 / 2$ & $\begin{array}{l}852.696 \\
826.231 \\
790.209\end{array}$ & $\begin{array}{l}-157.7(1.2) \\
-159.9(6) \\
-160.4(2.0)\end{array}$ & $-159.5(6)$ & $\begin{array}{c}- \\
-45(34) \\
-47(22)\end{array}$ & $-46.4(9)$ & $-169(9)$ & - & (3) \\
\hline 11044.08 & $4 \mathrm{~d}^{4}\left({ }^{3} \mathrm{H}\right) 5 \mathrm{~s}{ }^{4} \mathrm{H}$ & $9 / 2$ & $\begin{array}{l}834.601 \\
800.248 \\
770.737^{*}\end{array}$ & $\begin{array}{l}372(5) \\
372.7(6) \\
373.8(8)\end{array}$ & $373.1(4)$ & $\begin{array}{l}- \\
- \\
-\end{array}$ & & $372.9(7)$ & - & (3) \\
\hline 11247.88 & $4 \mathrm{~d}^{4}\left({ }^{3} \mathrm{H}\right) 5 \mathrm{~s}{ }^{4} \mathrm{H}$ & $11 / 2$ & $\begin{array}{l}771.680 \\
754.017^{*}\end{array}$ & $\begin{array}{l}593.8(1.2) \\
594.0(0.6)\end{array}$ & $593.9(1)$ & $\begin{array}{l}- \\
-\end{array}$ & & $592(3)$ & - & (3) \\
\hline 11524.65 & $4 \mathrm{~d}^{4}\left({ }^{3} \mathrm{H}\right) 5 \mathrm{~s}{ }^{4} \mathrm{H}$ & $13 / 2$ & 788.526 & $704.9(2.8)$ & & - & & $700(4)$ & - & (3) \\
\hline 12288.25 & $4 d^{4}\left({ }^{3} F\right) 5 s{ }^{4} F$ & $3 / 2$ & 800.755 & $-592.2(2.8)$ & & $35(24)$ & & $-592(2)$ & - & (1) \\
\hline 12357.70 & $4 d^{4}\left({ }^{3} F\right) 5 s{ }^{4} F$ & $9 / 2$ & 843.981 & $739.7(1.0)$ & & $10(50)$ & & $740(2)$ & - & (1) \\
\hline 12982.38 & $4 d^{4}\left({ }^{3} G\right) 5 s{ }^{4} G$ & $7 / 2$ & 758.320 & $568.2(4)$ & & - & & $563.9(2)$ & - & (3) \\
\hline 13145.71 & $4 d^{4}\left({ }^{3} G\right) 5 s{ }^{4} G$ & $9 / 2$ & $\begin{array}{l}829.365 \\
767.833 \\
751.977\end{array}$ & $\begin{array}{l}663.3(6) \\
662.3(1.0) \\
666(4)\end{array}$ & $663.1(4)$ & $\begin{array}{l}55(30) \\
74(18) \\
-\end{array}$ & $69.0(4)$ & $667(5)$ & - & (4) \\
\hline 13629.15 & $4 d^{3}\left({ }^{4} \mathrm{P}\right) 5 \mathrm{~s}^{2}{ }^{4} \mathrm{P}$ & $1 / 2$ & $\begin{array}{l}803.773 \\
773.586 \\
763.815 \\
751.237^{*}\end{array}$ & $\begin{array}{l}2938(3) \\
2938.7(1.8) \\
2939(3) \\
2945(9)\end{array}$ & $2938.8(6)$ & $\begin{array}{l}0 \\
0 \\
0 \\
0\end{array}$ & 0 & 2939.1(8) & 0 & (5) \\
\hline 14211.30 & $4 d^{4}\left({ }^{3} P\right) 5 s{ }^{4} P$ & $3 / 2$ & 821.125 & 1417.4(1.6) & & $15(24)$ & & $1414.5(2)$ & $31(4)$ & (5) \\
\hline 14899.26 & $4 d^{4}\left({ }^{3} P\right) 5 s{ }^{4} P$ & $5 / 2$ & $\begin{array}{l}798.005 \\
787.341 \\
786.266 \\
775.090 \\
758.526\end{array}$ & $\begin{array}{l}1016.0(8) \\
1018.9(6) \\
1017.2(2.0) \\
1016.6(1.0) \\
1016.9(1.6)\end{array}$ & 1017.6(6) & $\begin{array}{l}8(24) \\
4(32) \\
- \\
- \\
-\end{array}$ & $7(2)$ & - & - & \\
\hline 15282.35 & $4 d^{4}\left({ }^{3} D\right) 5 s{ }^{4} D$ & $7 / 2$ & $\begin{array}{l}827.769 \\
823.682 \\
754.338 \\
753.538\end{array}$ & $\begin{array}{l}982(8) \\
981.6(1.0) \\
981.2(1.2) \\
981.6(1.2)\end{array}$ & $981.5(1)$ & $\begin{array}{c}- \\
-24(18) \\
- \\
-17(26)\end{array}$ & $-22(3)$ & $988(5)$ & - & (1) \\
\hline 15439.25 & $4 d^{4}\left({ }^{3} D\right) 5 s{ }^{4} D$ & $3 / 2$ & $\begin{array}{l}817.623 \\
801.087 \\
790.932 \\
768.660 \\
762.557\end{array}$ & $\begin{array}{l}481.5(8) \\
482(3) \\
482.2(2.2) \\
480(3) \\
481.9(1.2)\end{array}$ & $481.6(2)$ & $\begin{array}{l}105(4) \\
111(24) \\
102(22) \\
116(30) \\
110(14)\end{array}$ & $106(1)$ & - & - & \\
\hline 15460.77 & $4 d^{4}\left({ }^{3} D\right) 5 s{ }^{4} D$ & $1 / 2$ & $\begin{array}{l}819.065 \\
802.471 \\
792.281\end{array}$ & $\begin{array}{l}-1134.7(2.0) \\
-1140(4) \\
-1135(4)\end{array}$ & $-1135.8(1.3)$ & $\begin{array}{l}0 \\
0 \\
0\end{array}$ & 0 & - & - & \\
\hline 15467.08 & $4 d^{4}\left({ }^{3} D\right) 5 s{ }^{4} D$ & $5 / 2$ & $\begin{array}{l}840.627 \\
810.783 \\
802.878 \\
770.308 \\
764.179\end{array}$ & $\begin{array}{l}833.4(2.8) \\
831.8(1.2) \\
833.1(1.6) \\
834.5(8) \\
832.7(1.2)\end{array}$ & $833.4(5)$ & $\begin{array}{l}-143(36) \\
-104(28) \\
-117(16) \\
-123(24) \\
-124(56)\end{array}$ & $-120(5)$ & - & - & \\
\hline 16828.52 & $4 d^{4}\left({ }^{1} G\right) 5 s{ }^{2} G$ & $9 / 2$ & 861.445 & $744.4(6)$ & & $57(12)$ & & $743.6(1.2)$ & - & (1) \\
\hline 17476.22 & $4 d^{4}\left({ }^{1} I\right) 5 s{ }^{2} I$ & $11 / 2$ & $786.255^{*}$ & $11(8)$ & & - & & $-20(19)$ & - & (3) \\
\hline 18332.04 & $4 d^{4}\left({ }^{3} H\right) 5 s{ }^{2} H$ & $11 / 2$ & $766.276^{*}$ & $2.9(6)$ & & $-94(44)$ & & - & - & \\
\hline 19034.71 & $4 d^{4}\left({ }^{3} G\right) 5 s{ }^{2} G$ & $7 / 2$ & $\begin{array}{l}833.743 \\
772.673 \\
\end{array}$ & $\begin{array}{l}478.3(1.4) \\
475.9(1.0) \\
\end{array}$ & $477.6(4)$ & $-\overline{57}(40)$ & & - & - & \\
\hline
\end{tabular}

Notes. Configurations and terms according to Kröger \& Bouzed (2003); the wavelength given in the fifth column specifies the line that was used to determine the $A_{\text {exp }}$ and $B_{\text {exp }}$ values; when a hyperfine structure constant was determined by more than one line, the weighted mean value $A_{\text {mean }}$ and $B_{\text {mean }}$, respectively, are given, calculated by using the error bar of $A_{\text {exp }}$ and $B_{\text {exp }}$ as weight. In columns $A_{\text {mean }}$ and $B_{\text {mean }}$, twice the standard deviation that resulted from the weighted mean value calculation is given as error. ${ }^{(*)}$ Hyperfine structure constants of upper level were fixed during the fit.

References. (1) Başar et al. (2008); (2) Fraenkel et al. (1988); (3) Er et al. (2011); (4) Kröger (2007); (5) Bouzed et al. (2003). 
Table 3. continued.

\begin{tabular}{|c|c|c|c|c|c|c|c|c|c|c|}
\hline$E\left(\mathrm{~cm}^{-1}\right)$ & Config., Term & $J$ & $\lambda_{\text {air }}(\mathrm{nm})$ & $A_{\exp }(\mathrm{MHz})$ & $A_{\text {mean }}(\mathrm{MHz})$ & $B_{\exp }(\mathrm{MHz})$ & $B_{\text {mean }}(\mathrm{MHz})$ & $A_{\text {ref }}(\mathrm{MHz})$ & $B_{\text {ref }}(\mathrm{MHz})$ & Ref. \\
\hline & & & 765.904 & $477.4(8)$ & & - & & & & \\
\hline & & & 758.561 & $477.6(4)$ & & - & & & & \\
\hline & & & 751.759 & $482.2(1.6)$ & & - & & & & \\
\hline \multirow[t]{3}{*}{19556.91} & $4 d^{4}\left({ }^{3} G\right) 5 s^{2} G$ & $9 / 2$ & 845.672 & $112.8(6)$ & $112.7(1)$ & $17(12)$ & $-12(25)$ & - & - & \\
\hline & & & 789.857 & $112.3(1.2)$ & & $-33(10)$ & & & & \\
\hline & & & 766.161 & $112.6(1.6)$ & & - & & & & \\
\hline \multirow[t]{3}{*}{19568.72} & $4 d^{4}\left({ }^{1} F\right) 5 s{ }^{2} F$ & $5 / 2$ & 808.515 & $322.4(1.0)$ & $322.4(2)$ & - & & - & - & \\
\hline & & & 788.429 & $322.6(1.4)$ & & - & & & & \\
\hline & & & 773.026 & $319.8(1.4)$ & & - & & & & \\
\hline \multirow[t]{5}{*}{19931.98} & $4 d^{4}\left({ }^{3} D\right) 5 s{ }^{2} D$ & $5 / 2$ & 842.317 & $531(11)$ & $529.0(6)$ & - & & - & - & \\
\hline & & & 827.490 & $528(14)$ & & - & & & & \\
\hline & & & 811.682 & $529(5)$ & & - & & & & \\
\hline & & & 787.741 & $529.9(1.8)$ & & - & & & & \\
\hline & & & 785.793 & $527.5(2.2)$ & & - & & & & \\
\hline \multirow[t]{6}{*}{20060.84} & $4 d^{4}\left({ }^{3} F\right) 5 s{ }^{2} F$ & $7 / 2$ & 839.231 & $242.5(2.4)$ & $244.5(3)$ & $23(24)$ & $2(3)$ & - & - & \\
\hline & & & 822.609 & $242.3(1.2)$ & & $13(22)$ & & & & \\
\hline & & & 803.606 & $244.6(2)$ & & $1(4)$ & & & & \\
\hline & & & 778.709 & $238(4)$ & & - & & & & \\
\hline & & & 777.208 & $242.9(2.2)$ & & - & & & & \\
\hline & & & 772.403 & $242.1(1.4)$ & & $11(80)$ & & & & \\
\hline 22936.90 & $4 d^{5}{ }^{4} G$ & $7 / 2$ & 818.103 & $266(5)$ & & - & & - & - & \\
\hline 23010.58 & $4 d^{5}{ }^{4} G$ & $9 / 2$ & $810.526^{*}$ & $94(10)$ & & - & & - & - & \\
\hline 23048.58 & $4 d^{5}{ }^{4} G$ & $11 / 2$ & 794.565 & $82(4)$ & & - & & - & - & \\
\hline
\end{tabular}

\section{Results and discussion}

Altogether, 81 spectral lines were investigated by laser excitation i.e LOGS and LIFS. They are listed in Table 1 along with their wavelengths in air $\lambda_{\text {air }}$, wave numbers in vacuum $\sigma_{\text {vac }}$, intensities and classifications. In the last column of Table 1, the experimental method used, LOGS or LIFS, is specified. When LIFS was used, the corresponding fluorescence wavelength is given in the last column. The wave numbers in vacuum were calculated as energy differences from the upper and lower level: $\sigma_{\text {vac }}=E_{\mathrm{u}}-E_{\mathrm{l}}$. The experimental centre of the gravity wave number in vacuum of the lines can be determined by using the start wave number of laser scan and fitting the centre of gravity of the hfs. These experimental values agree within an interval of $\pm 0.02 \mathrm{~cm}^{-1}$ with the calculated wave number $\sigma_{\text {vac }}$ given in Table 1. The wavelengths in air were calculated from the wave numbers in vacuum using the dispersion relation (Peck \& Reader 1972). The intensities and classifications are given according to Humphreys \& Meggers (1945) when a line was listed in this wavelength table. Nineteen lines are new lines, which mean they have not previously been published. They are denoted as "nl". Additionally, 16 lines measured in the present work were given in the wavelength tables of Humphreys \& Meggers (1945) without classification. They have newly been classified here and are denoted as "nc". When a line is overlapping within its hfs pattern with another $\mathrm{Nb}$ or with a $\mathrm{Ne}$ line, this is commented as " $\mathrm{B}$ " (blend) in Table 1.

The resulting hfs constants $A_{\exp }$ and $B_{\text {exp }}$ are listed in Tables 3 and 4 for the levels of even and odd parity, respectively. Level energies are given according to Humphreys \& Meggers (1945) and Kröger et al. (2004, 2007), configurations and terms according to Kröger \& Bouzed (2003) for levels of even parity and according to Kröger et al. (2007) for levels of odd parity. The wavelength $\lambda_{\text {air }}$ given in the fifth column specifies the line that was used to determine the hfs constants $A_{\text {exp }}$ and $B_{\text {exp }}$. All spectra were recorded and fitted five times or more, depending on the signal-to-noise ratio. The given $A_{\exp }$ and $B_{\exp }$ are the statistic mean value of the fit results of all measurements, the measurement uncertainty being twice the corresponding standard. These errors refer only to the statistical variation of the fit and do not include systematic errors, which may occur because of the coupling of profile or intensity parameters during the fit. Hence the measurement uncertainty may be higher than the given statistical error bar. This fact can be exemplified by some hfs constants $A_{\text {exp }}$ or $B_{\text {exp }}$, determined from different lines, which do not agree with each other within the limits of given errors. Nevertheless, the statistical errors convey an idea of the accuracy of the fit value.

When a hfs constant of a level was measured by two or more lines, the weighted mean value $A_{\text {mean }}$ and $B_{\text {mean }}$ was taken, using the error limits of $A_{\exp }$ and $B_{\exp }$ as weight. The measurement uncertainties given for the mean values $A_{\text {mean }}$ are twice the standard deviations corresponding to this average.

\section{Conclusion and outlook}

In total, we have determined the magnetic dipole hyperfine structure constants $A$ for 81 energy levels of atomic $\mathrm{Nb}$ and additionally the electric quadrupole hyperfine structure constants $B$ for 41 of these levels. For 13 levels of even parity and for 11 levels of odd parity the $A$ constants were measured for the first time. Additionally, the electric quadrupole hfs constants $B$ for $30 \mathrm{lev}$ els were measured for the first time. Beyond that, already known $A$ and $B$ constants were verified and in some cases the accuracy was improved.

The present work constitutes another contribution to complete the hfs data of atomic $\mathrm{Nb}$ and provides this data for users, especially in astrophysics. Including the new results of the present work, the magnetic dipole hfs constants $A$ are now known for all known energy levels of even parity. 
Gö. Başar et al.: Hfs investigations of Nb I with LOGS and LIFS in the near-IR

Table 4. Experimental hyperfine structure constants $A_{\text {exp }}$ and $B_{\text {exp }}$ (in $\mathrm{MHz}$ ) of the levels of odd parity of $\mathrm{Nb}$ I together with comparative values $A_{\text {ref }}$ and $B_{\text {ref }}$, if available.

\begin{tabular}{|c|c|c|c|c|c|c|c|c|c|c|}
\hline$E\left(\mathrm{~cm}^{-1}\right)$ & Config., Term & $J$ & $\lambda_{\text {air }}(\mathrm{nm})$ & $A_{\exp }(\mathrm{MHz})$ & $A_{\text {mean }}(\mathrm{MHz})$ & $B_{\exp }(\mathrm{MHz})$ & $B_{\text {mean }}(\mathrm{MHz})$ & $A_{\text {ref }}(\mathrm{MHz})$ & $B_{\text {ref }}(\mathrm{MHz})$ & Ref. \\
\hline 20107.36 & $4 d^{3}\left({ }^{4} F\right) 5 s\left({ }^{5} F\right) 5 p{ }^{4} D$ & $1 / 2$ & 854.725 & $-794.1(2.6)$ & & 0 & & $-794.7(5)$ & 0 & (6) \\
\hline 20383.62 & $4 d^{3}\left({ }^{4} F\right) 5 s\left({ }^{5} F\right) 5 p{ }^{4} D$ & $3 / 2$ & 835.003 & $597.4(4)$ & & $-14(6)$ & & $597.8(5)$ & $-13(4)$ & (1) \\
\hline 20837.98 & $4 d^{3}\left({ }^{4} F\right) 5 s\left({ }^{5} F\right) 5 p{ }^{4} D$ & $5 / 2$ & 847.596 & $808.6(6)$ & & $-15(14)$ & & $808.8(4)$ & $-14(6)$ & (1) \\
\hline 21512.18 & $4 d^{3}\left({ }^{4} F\right) 5 s\left({ }^{5} F\right) 5 p{ }^{4} D$ & $7 / 2$ & 801.766 & $871.9(6)$ & & $-24(16)$ & & $872.8(5)$ & $-27(6)$ & (1) \\
\hline 22647.03 & $4 d^{3}\left({ }^{4} F\right) 5 s\left({ }^{5} F\right) 5 p{ }^{4} G$ & $5 / 2$ & 852.696 & $-74.3(1.4)$ & & - & & $-78.5(2)$ & - & (6) \\
\hline 23022.56 & $4 d^{3}\left({ }^{4} F\right) 5 s\left({ }^{5} F\right) 5 p{ }^{4} G$ & $7 / 2$ & $\begin{array}{l}826.231 \\
834.601\end{array}$ & $\begin{array}{l}430.1(6) \\
424(7)\end{array}$ & $430.1(5)$ & $\begin{array}{l}1(16) \\
-\end{array}$ & & $430.3(2)$ & - & (6) \\
\hline 23243.87 & $4 d^{3}\left({ }^{4} F\right) 5 s\left({ }^{5} F\right) 5 p{ }^{4} F$ & $3 / 2$ & $762.113^{*}$ & $-14.4(6)$ & & - & & $-16.6(3)$ & - & (6) \\
\hline 23536.77 & $4 d^{3}\left({ }^{4} F\right) 5 s\left({ }^{5} F\right) 5 p{ }^{4} G$ & $9 / 2$ & $\begin{array}{l}800.248 \\
813.519^{*}\end{array}$ & $\begin{array}{l}629.9(1.0) \\
629(4)\end{array}$ & $629.9(2)$ & $\begin{array}{l}- \\
-\end{array}$ & & $632.6(1)$ & - & (6) \\
\hline 23574.14 & $4 d^{3}\left({ }^{4} F\right) 5 s\left({ }^{5} F\right) 5 p{ }^{4} F$ & $5 / 2$ & 790.209 & $512(4)$ & & $102(26)$ & & $514.1(2)$ & $67(5)$ & (1) \\
\hline 24203.05 & $4 d^{3}\left({ }^{4} F\right) 5 s\left({ }^{5} F\right) 5 p{ }^{4} G$ & $11 / 2$ & $\begin{array}{l}771.680 \\
788.526 \\
843.981\end{array}$ & $\begin{array}{l}751.3(1.0) \\
754.3(2.2) \\
748.8(8)\end{array}$ & $750.1(1.2)$ & $\begin{array}{l}- \\
- \\
0(60)\end{array}$ & & $752.3(1)$ & - & (6) \\
\hline 24773.03 & $4 d^{3}\left({ }^{4} F\right) 5 s\left({ }^{3} F\right) 5 p{ }^{2} D$ & $5 / 2$ & 800.755 & $170.5(1.2)$ & & $17(40)$ & & $170.1(5)$ & $-11(7)$ & (1) \\
\hline 25199.81 & $4 d^{4}\left({ }^{5} D\right) 5 p{ }^{6} F$ & $9 / 2$ & 829.365 & $113.1(4)$ & & $33(32)$ & & $112.4(4)$ & - & (6) \\
\hline 26067.06 & $4 d^{3}\left({ }^{4} \mathrm{P}\right) 5 \mathrm{~s}\left({ }^{5} \mathrm{P}\right) 5 \mathrm{p}{ }^{6} \mathrm{D}$ & $3 / 2$ & 803.773 & $938.9(1.2)$ & & $49(32)$ & & $943.5(1.8)$ & $79(3)$ & $(5)$ \\
\hline 26165.79 & $4 d^{4}\left({ }^{5} D\right) 5 p{ }^{6} F$ & $7 / 2$ & $\begin{array}{l}758.320 \\
767.833\end{array}$ & $\begin{array}{l}299.1(4) \\
294.9(1.2)\end{array}$ & $298.7(1.3)$ & $-\overline{65}(20)$ & & $297.6(7)$ & - & (6) \\
\hline 26386.36 & $4 d^{3}\left({ }^{4} P\right) 5 s\left({ }^{5} P\right) 5 p{ }^{6} D$ & $5 / 2$ & 821.125 & $810.9(1.0)$ & & $64(68)$ & & $809.2(5)$ & $64.2(9.3)$ & (2) \\
\hline 26440.33 & $4 d^{4}\left({ }^{5} D\right) 5 p{ }^{4} F$ & $9 / 2$ & 751.977 & $342(8)$ & & - & & $337.6(2)$ & $88.6(8.1)$ & (2) \\
\hline 26552.40 & $4 d^{4}\left({ }^{5} D\right) 5 p{ }^{6} D$ & $1 / 2$ & 773.586 & $430.3(1.8)$ & & 0 & & $430.1(5)$ & 0 & (2) \\
\hline 26717.73 & $4 d^{3}\left({ }^{4} F\right) 5 s\left({ }^{3} F\right) 5 p{ }^{4} D$ & $1 / 2$ & 763.815 & $507.0(2.8)$ & & 0 & & $508.3(4)$ & 0 & (2) \\
\hline 26896.68 & $4 d^{3}\left({ }^{2} G\right) 5 s\left({ }^{3} G\right) 5 p{ }^{4} H$ & $7 / 2$ & $833.284^{*}$ & $181.3(2.8)$ & & $-21(40)$ & & - & - & \\
\hline 26936.86 & $4 d^{4}\left({ }^{5} D\right) 5 p{ }^{6} D$ & $3 / 2$ & $785.604^{*}$ & $39.9(1.6)$ & & - & & $39.9(6)$ & - & (6) \\
\hline 27359.70 & $4 d^{4}\left({ }^{5} D\right) 5 p{ }^{4} D$ & $5 / 2$ & $\begin{array}{l}827.769 \\
840.627\end{array}$ & $\begin{array}{l}-20(10) \\
-20(3)\end{array}$ & $-20(0)$ & $-\overline{11(32)}$ & & $-22.4(1.2)$ & - & (6) \\
\hline 27419.62 & $4 d^{3}\left({ }^{4} P\right) 5 s\left({ }^{5} P\right) 5 p{ }^{6} D$ & $9 / 2$ & 823.682 & $405.7(8)$ & & $47(16)$ & & $405.4(9)$ & $94(20)$ & $(5)$ \\
\hline 27427.07 & $4 d^{4}\left({ }^{5} D\right) 5 p{ }^{6} D$ & $7 / 2$ & 798.005 & $385.8(4)$ & & $-52(32)$ & & $386.0(5)$ & $-38.2(15.2)$ & (2) \\
\hline 27596.74 & $4 d^{4}\left({ }^{5} D\right) 5 p{ }^{4} D$ & $7 / 2$ & 787.341 & $-149.3(8)$ & & $60(20)$ & & $-151.4(7)$ & - & (3) \\
\hline 27614.10 & $4 d^{3}\left({ }^{2} P\right) 5 s\left({ }^{3} P\right) 5 p{ }^{4} P$ & $5 / 2$ & 786.266 & $616.2(1.6)$ & & - & & $615(2)$ & - & (1) \\
\hline 27666.46 & $4 d^{3}\left({ }^{2} P\right) 5 s\left({ }^{3} P\right) 5 p{ }^{4} D$ & $1 / 2$ & $\begin{array}{l}817.623 \\
819.065\end{array}$ & $\begin{array}{l}725.5(1.6) \\
726.2(1.0)\end{array}$ & $726.0(3)$ & $\begin{array}{l}0 \\
0\end{array}$ & & $729.7(2.3)$ & 0 & (6) \\
\hline 27797.44 & $4 d^{3}\left({ }^{4} F\right) 5 s\left({ }^{3} F\right) 5 p{ }^{2} F$ & $5 / 2$ & $\begin{array}{l}775.090 \\
810.783\end{array}$ & $\begin{array}{l}569.0(6) \\
567.4(8)\end{array}$ & $568.4(8)$ & $-\overline{24}(14)$ & & $568.4(4.9)$ & - & (6) \\
\hline 27918.85 & $4 d^{4}\left({ }^{5} D\right) 5 p{ }^{4} D$ & $3 / 2$ & $\begin{array}{l}801.087 \\
802.471 \\
802.878\end{array}$ & $\begin{array}{l}344.7(2.4) \\
343.7(1.4) \\
344.4(1.4)\end{array}$ & $344.2(3)$ & $\begin{array}{l}-33(12) \\
-24(16) \\
-35(6)\end{array}$ & $-33.5(2.3)$ & $348(1)$ & - & (6) \\
\hline 28079.09 & $4 d^{3}\left({ }^{4} \mathrm{P}\right) 5 \mathrm{~s}\left({ }^{5} \mathrm{P}\right) 5 \mathrm{p}{ }^{4} \mathrm{P}$ & $3 / 2$ & $\begin{array}{l}758.526 \\
790.932 \\
792.281\end{array}$ & $\begin{array}{l}677.8(1.6) \\
676.8(2.2) \\
676.1(1.2)\end{array}$ & $676.8(5)$ & $\begin{array}{l}-36(24) \\
-34(8) \\
-36(10)\end{array}$ & $-34.9(7)$ & $676.2(3)$ & - & (6) \\
\hline 28433.74 & $4 d^{3}\left({ }^{4} F\right) 5 s\left({ }^{3} F\right) 5 p{ }^{2} G$ & $9 / 2$ & 861.445 & $178.5(6)$ & & $-60(6)$ & & $179.5(4)$ & $-48(12)$ & (1) \\
\hline 28445.33 & $4 d^{3}\left({ }^{4} P\right) 5 s\left({ }^{5} P\right) 5 p{ }^{4} P$ & $5 / 2$ & $\begin{array}{l}770.308 \\
768.660\end{array}$ & $\begin{array}{l}617.0(1.0) \\
613.9(2.0)\end{array}$ & $616.4(1.2)$ & $\begin{array}{l}-75(20) \\
-47(46)\end{array}$ & $-70(10)$ & $614(1)$ & - & (6) \\
\hline 28535.36 & $4 d^{3}\left({ }^{2} \mathrm{P}\right) 5 \mathrm{~s}\left({ }^{3} \mathrm{P}\right) 5 \mathrm{p}{ }^{4} \mathrm{D}$ & $7 / 2$ & 754.338 & $659.2(1.0)$ & & - & & $660.5(9)$ & - & (6) \\
\hline 28549.42 & $4 d^{3}\left({ }^{4} P\right) 5 s\left({ }^{5} P\right) 5 p{ }^{4} P$ & $5 / 2$ & $\begin{array}{l}753.538 \\
762.557 \\
\end{array}$ & $\begin{array}{l}676.7(1.0) \\
677.3(6)\end{array}$ & $677.0(3)$ & $\begin{array}{r}-13(22) \\
1(28)\end{array}$ & $-9(5)$ & $676.9(9)$ & - & (6) \\
\hline
\end{tabular}

Notes. Configurations and terms according to Kröger et al. (2007); the wavelength given in the fifth column specifies the line that was used to determine the $A_{\exp }$ and $B_{\exp }$ values; when a hyperfine structure constant was determined by more than one line, the weighted mean value $A_{\text {mean }}$ and $A_{\text {mean }}$, respectively, are calculated, using error bar of $A_{\exp }$ and $B_{\exp }$ as weight. In column $A_{\text {mean }}$, twice the standard deviation that resulted from the weighted mean value calculation is given as error. ${ }^{(*)}$ Hyperfine structure constants of lower level were fixed during the fit.

References. (1) Başar et al. (2008); (2) Fraenkel et al. (1988); (3) Er et al. (2011); (4) Kröger (2007); (5) Bouzed et al. (2003); (6) Kröger et al. (2010). 
Table 4. continued.

\begin{tabular}{|c|c|c|c|c|c|c|c|c|c|c|}
\hline$E\left(\mathrm{~cm}^{-1}\right)$ & Config., Term & $J$ & $\lambda_{\text {air }}(\mathrm{nm})$ & $A_{\text {exp }}(\mathrm{MHz})$ & $A_{\text {mean }}(\mathrm{MHz})$ & $B_{\exp }(\mathrm{MHz})$ & $B_{\text {mean }}(\mathrm{MHz})$ & $A_{\text {ref }}(\mathrm{MHz})$ & $B_{\text {ref }}(\mathrm{MHz})$ & Ref \\
\hline & & & 764.179 & $676.1(1.6)$ & & $-22(70)$ & & & & \\
\hline 31025.52 & $4 d^{3}\left({ }^{4} F\right) 5 s\left({ }^{3} F\right) 5 p{ }^{2} F$ & $7 / 2$ & 833.743 & $361.7(1.2)$ & & - & & - & - & \\
\hline 31378.58 & $4 d^{3}\left({ }^{2} \mathrm{G}\right) 5 \mathrm{~s}\left({ }^{1} \mathrm{G}\right) 5 \mathrm{p}{ }^{2} \mathrm{H}$ & $11 / 2$ & 845.672 & $791.1(1.2)$ & & $-236(50)$ & & - & - & \\
\hline 31800.74 & $4 d^{3}\left({ }^{2} G\right) 5 s\left({ }^{3} G\right) 5 p^{2} G$ & $7 / 2$ & 842.317 & $220(7)$ & & - & & $217.4(9)$ & - & (6) \\
\hline 31807.55 & $4 d^{3}\left({ }^{2} D_{2}\right) 5 s\left({ }^{3} D\right) 5 p{ }^{4} D$ & $5 / 2$ & $\begin{array}{l}816.847^{*} \\
782.696^{*}\end{array}$ & $\begin{array}{l}450(8) \\
453(6)\end{array}$ & $451.9(1.4)$ & - & & - & - & \\
\hline 31933.68 & $4 d^{3}\left({ }^{4} F\right) 5 s\left({ }^{3} F\right) 5 p{ }^{4} G$ & $5 / 2$ & 808.515 & $567.5(1.4)$ & & - & & - & - & \\
\hline 31973.24 & $4 d^{3}\left({ }^{2} D_{2}\right) 5 s\left({ }^{3} D\right) 5 p{ }^{4} D$ & $7 / 2$ & $\begin{array}{l}772.673 \\
839.231\end{array}$ & $\begin{array}{l}742.5(1.0) \\
742.9(2.4)\end{array}$ & $742.6(1)$ & $\begin{array}{l}56(44) \\
50(40)\end{array}$ & $53(3)$ & - & - & \\
\hline 32013.40 & $4 d^{3}\left({ }^{2} D_{2}\right) 5 s\left({ }^{3} D\right) 5 p{ }^{4} F$ & $5 / 2$ & 827.490 & $538(14)$ & & - & & - & - & \\
\hline 32087.58 & $4 d^{4}\left({ }^{3} H\right) 5 p^{2} G$ & $7 / 2$ & 765.904 & $317.7(8)$ & & - & & $316(2)$ & - & (1) \\
\hline 32213.94 & $4 d^{3}\left({ }^{2} H\right) 5 s\left({ }^{3} H\right) 5 p{ }^{4} I$ & $9 / 2$ & $\begin{array}{l}758.561 \\
789.857 \\
822.609\end{array}$ & $\begin{array}{l}594.7(4) \\
594.5(1.8) \\
593.2(2.0)\end{array}$ & $594.6(2)$ & $\begin{array}{c}- \\
-14(32) \\
35(52)\end{array}$ & $-1(22)$ & $594.8(1.5)$ & - & (6) \\
\hline 32248.69 & $4 d^{3}\left({ }^{4} P\right) 5 s\left({ }^{5} P\right) 5 p{ }^{4} D$ & $3 / 2$ & $\begin{array}{l}811.682 \\
788.429\end{array}$ & $\begin{array}{l}594(6) \\
593.5(2.6)\end{array}$ & $593.6(2)$ & - & & - & - & \\
\hline 32333.18 & $4 d^{3}\left({ }^{2} D_{2}\right) 5 s\left({ }^{3} D\right) 5 p{ }^{4} F$ & $7 / 2$ & 751.759 & $451.3(1.2)$ & & - & & $451.3(4.4)$ & - & (6) \\
\hline 32501.33 & $4 d^{4}\left({ }^{3} H\right) 5 p{ }^{2} G$ & $7 / 2$ & $\begin{array}{l}803.606 \\
773.026\end{array}$ & $\begin{array}{l}593.8(1.2) \\
591.0(1.0)\end{array}$ & $592.2(1.4)$ & $\begin{array}{c}-25(14) \\
-\end{array}$ & & $589.7(1.7)$ & - & (3) \\
\hline 32605.39 & $4 d^{4}\left({ }^{3} H\right) 5 p{ }^{2} G$ & $9 / 2$ & 766.161 & $272.5(1.6)$ & & - & & $270.5(1)$ & - & (6) \\
\hline 32623.02 & $4 d^{3}\left({ }^{4} P\right) 5 s\left({ }^{3} P\right) 5 p{ }^{2} P$ & $3 / 2$ & 787.741 & $499.5(2.2)$ & & - & & - & - & \\
\hline 32654.48 & $4 d^{3}\left({ }^{4} F\right) 5 s\left({ }^{3} F\right) 5 p{ }^{4} F$ & $5 / 2$ & $\begin{array}{l}763.979^{*} \\
785.793\end{array}$ & $\begin{array}{l}330(14) \\
318.3(1.8)\end{array}$ & $318.5(1.5)$ & - & & $321(11)$ & - & (6) \\
\hline 32899.08 & $4 d^{3}\left({ }^{4} F\right) 5 s\left({ }^{3} F\right) 5 p{ }^{4} F$ & $7 / 2$ & 778.709 & $203(5)$ & & - & & $218.4(12.1)$ & - & (6) \\
\hline 32923.87 & $4 d^{3}\left({ }^{2} D_{2}\right) 5 s\left({ }^{3} D\right) 5 p{ }^{4} F$ & $9 / 2$ & 777.208 & $667.4(1.6)$ & & $-110(100)$ & & $668.9(3.1)$ & - & (3) \\
\hline 33003.89 & $4 d^{3}\left({ }^{4} P\right) 5 s\left({ }^{5} P\right) 5 p{ }^{4} D$ & $7 / 2$ & 772.403 & $441(4)$ & & - & & - & - & \\
\hline 35156.94 & $4 d^{3}\left({ }^{2} H\right) 5 s\left({ }^{3} H\right) 5 p{ }^{4} G$ & $9 / 2$ & 818.103 & $517(5)$ & & - & & $510.0(3.1)$ & - & (6) \\
\hline 35630.62 & $4 d^{3}\left({ }^{2} \mathrm{H}\right) 5 \mathrm{~s}\left({ }^{3} \mathrm{H}\right) 5 \mathrm{p}{ }^{4} \mathrm{G}$ & $11 / 2$ & 794.565 & $548(4)$ & & - & & - & - & \\
\hline
\end{tabular}

Based on these data, it is highly recommended that an improved theoretical analysis for levels of even and odd parity is undertaken. Additionally, the search for new fine structure energy levels should proceed. From an atomic physical point of view, it would be of great interest to measure the hfs constants, especially the electric quadrupole constants $B$, with higher accuracy using Doppler-free experimental methods.

Acknowledgements. Gö. Başar thanks for the research fund of the Istanbul University Scientific Research Projects with project number No. 6222. I. K. Öztürk thanks for the research fund of the Istanbul University Scientific Research Projects with project number No. 6221. We thank Ali Sami Gözükırmızı for the data acquisition program.

\section{References}

Başar, G., Başar, G., Bayram, B., \& Kröger, S. 2008, Phys. Scr., 78, 015303 Bouzed, A., Kröger, S., Zimmermann, D., Kronfeldt, H.-D., \& Guthöhrlein, G. 2003, Eur. Phys. J. D, 23, 57

Büttgenbach, S., \& Dicke, R. 1975, Z. Phys. D, 275, 197
Büttgenbach, S., Dicke, R., Gebauer, H., Herschel, M., \& Meisel, G. 1975, Z Phys. D, 275, 193

Er, A., Öztürk, I., Başar, G., et al. 2011, J. Phys. B: At. Mol. Opt. Phys., 44

Fraenkel, L., Bengtsson, C., Hanstorp, D., Nyberg, A., \& Persson, J. 1988, Z. Phys. D, 8, 171

Guthöhrlein, G. H. 2004, University of Bundeswehr Hamburg, unpublished Humphreys, C. J., \& Meggers, W. F. 1945, J. Res. Nat. Bur. Stand, 34, 478 Kröger, S. 2007, Eur. Phys. J. D, 41, 55

Kröger, S., \& Bouzed, A. 2003, Eur. Phys. J. D, 23, 63

Kröger, S., Scharf, O., \& Guthöhrlein, G. 2004, Europhys. Lett., 66, 344 Kröger, S., Öztürk, I. K., Acar, F. G., et al. 2007, Eur. Phys. J. D, 41, 61

Kröger, S., Er, A., Öztürk, I. K., et al. 2010, A\&A, 516, A1

Lederer, C. M., \& Shirley, V. S. 1978, Table of isotopes, 7th edn (New York: Wiley)

Messnarz, D., \& Guthöhrlein, G. H. 2000, Eur. Phys. J. D, 12, 269

NIST 2013, NIST Atomic Spectra Database Version 5, Website

Peck, R., \& Reader, K. 1972, JOSA, 62

Sasso, A. 1990, Rev. Mod. Phys., 82, 603

Shamim, K., Siddiqui, I., \& Windholz, L. 2011, Eur. Phys. J. D, 64

Singh, R., \& Rao, G. N. 1989, Phys. Scr., 40, 170

Singh, R., Thareja, R. K., \& Rao, G. N. 1992, J. Opt. Soc. Am. B, 9, 493

Windholz, L., \& Guthöhrlein, G. H. 2003, Phys. Scr. T, 105, 55 